\title{
Subsets of Macrophages and Dendritic Cells in Nonobese Diabetic Mouse Pancreatic Inflammatory Infiltrates: Correlation with the Development of Diabetes
}

\author{
Judith G. M. Rosmalen, Tracy Martin, Cathleen Dobbs, Jane S. A. Voerman, \\ Hemmo A. Drexhage, Kathryn Haskins, and Pieter J. M. Leenen
}

Department of Immunology (JGMR, JSAV, HAD, PJML), Erasmus University, Rotterdam, The Netherlands; Barbara Davis Center for Childhood Diabetes and Department of Immunology (TM, CD, KH), University of Colorado Health Sciences Center, Denver, Colorado

SUMMARY: Islet-specific T cells are essential in the development of type I diabetes. The role of non-lymphoid cells is relatively unclear, although infiltration of dendritic cells and macrophages is the first sign of islet autoimmunity in diabetes-prone nonobese diabetic (NOD) mice. BDC2.5 is one of the autoreactive T cell clones isolated from NOD mice. Transfer of BDC2.5 T cells into young NOD mice accelerates diabetes development, whereas transgenic expression of the BDC2.5 T cell receptor on NOD T cells (BDC2.5 TCR-Tg NOD) markedly reduces diabetes development. We show that, although the same antigen-specificity is involved, both models differ significantly in insulitis. BDC2.5 TCR-Tg NOD mice develop an extensive, but non-aggressive, peri-insulitis by 3 weeks of age. In these large peri-islet infiltrates, resembling secondary lymphoid tissue, BM ${ }^{+}$macrophages $(\mathrm{M} \phi)$ are virtually absent. In contrast, BDC2.5 T cell clone transfer results in an aggressive insulitis with small infiltrates, but relatively large numbers of $\mathrm{BM}^{+} \mathrm{M} \phi$. Infiltration of $\mathrm{BM}^{+} \mathrm{M} \phi$ therefore correlates with islet destruction. This is, however, not observed for all $\mathrm{M} \phi$; Monts- $4^{+} \mathrm{M} \phi$ follow a reverse pattern and are present in higher numbers in BDC2.5 TCR-Tg than in transferred mice. ER-MP23 ${ }^{+} \mathrm{M} \phi$ are reduced in both transferred and transgenic mice compared with wild-type NOD. Thus, this study underlines and extends previous data suggesting that $\mathrm{M} \phi$ are implicated in both early and late phases in diabetes development. Furthermore, our data imply that subsets of non-lymphoid cells have different roles in diabetes development. It is, therefore, important to recognize this heterogeneity when interpreting both in vivo and in vitro studies concerning non-lymphoid cells in diabetes. (Lab Invest 2000, 80:23-30).

$$
T
$$
ype I diabetes mellitus is the result of an autoimmune destruction of the $\beta$ cells in the islets of Langerhans (reviewed in Tisch and McDevitt, 1996). The disease is characterized by a very long pre-clinical period. In this period, several types of leukocytes accumulate first around the islets (a process called peri-insulitis) and subsequently infiltrate into the islets (insulitis). It is only when the vast majority of pancreatic $\beta$ cells are destroyed that the alteration of glucose-linked metabolism generates the classical signs of diabetes. The extensive preclinical period provides a tool for prediction and prevention of the disease.

To study the development of type I diabetes, animal models such as the nonobese diabetic (NOD) mouse and the BioBreeding $(\mathrm{BB})$ rat have been employed. In both models, the first sign of islet autoimmunity is an

Received August 19, 1999.

Address reprint requests to: Dr. J.G.M. Rosmalen, Department of Immunology, Erasmus University Rotterdam, P.O. Box 1738, 3000 DR Rotterdam, The Netherlands. Fax: 31-10408 9456; E-mail: rosmalen@ immu.fgg.eur.nl accumulation of antigen presenting cells (APC) around and in the islets (Voorbij et al, 1989; Jansen et al, 1994). These APC include various types of dendritic cells (DC) and macrophages $(\mathrm{M} \phi)$. $\mathrm{DC}$ and $\mathrm{M} \phi$ are characterized in the NOD mouse by markers such as CD11c, ER-MP23, and MOMA-1 (Jansen et al, 1994) and in the BB rat by MHC class II and ED1, but absence of acid phosphatase (Voorbij et al, 1989). The exact role of the different subtypes of myeloid cells is not known. Early infiltrating DC and accessory $\mathrm{M} \phi$ are thought to pick up relevant autoantigens and to migrate to the draining lymph nodes to present the islet antigens in the paracortical area to recirculating lymphocytes. B cells (Serreze et al, 1996) and CD8 ${ }^{+} \mathrm{T}$ cells (Wang et al, 1996) are probably also important in these very early phases of the insulitis process, but these cells occur only at relatively low frequencies. In time, the phase of peri-islet accumulation of APC is followed by a reaction of the draining lymph nodes and an accumulation of $B$ and $T$ lymphocytes around the islets, the latter in close apposition to the already accumulated APC (Jansen et al, 1994). The actual $\beta$ cell killing is histologically characterized by an infiltration into the islets of $\mathrm{M} \phi$, whereas $\mathrm{CD}^{+} \mathrm{T}$ cells (Wang 
et al, 1996) are also seen to infiltrate the islet. The histopathological picture of infiltration with scavenger type $\mathrm{M} \phi$ is compatible with the view that $\beta$ cell killing is at least in part a Th1 phenomenon (Katz et al, 1995; Liblau et al, 1995), where T cell-derived cytokines such as interferon- $\gamma$ activate $\mathrm{M} \phi$.

In the destruction of the $\beta$ cells, T cells are crucial. From the NOD mouse, several islet-specific diabetogenic $\mathrm{T}$ cell clones have been isolated. One of these is the CD4 ${ }^{+} \mathrm{T}$ cell clone BDC2.5 (Haskins et al, 1988), reactive to an as-yet unknown antigen localized on the membrane of the $\beta$ cell granule (Bergman and Haskins, 1994). Its in vitro cytokine profile is consistent with the phenotype of a Th1 cell (Peterson and Haskins, 1996) and the clone is able to transfer insulitis and diabetes to young NOD mice (Haskins and McDuffie, 1990). Although the transferred insulitis is characterized by a relatively small lymphocyte infiltration, a rapid progression to diabetes (within 2 to 3 weeks) is observed (Haskins and McDuffie, 1990).

Furthermore, a mouse model has been developed based on the transgenic (Tg) expression of the rearranged $\mathrm{T}$ cell receptor (TCR) genes from the BDC2.5 T cell clone on a NOD background (Katz et al, 1993). In contrast to the wild-type NOD, this TCR-transgenic NOD model is characterized by an extensive lymphocyte infiltration from 3 weeks of age onward. However, the diabetes incidence of BDC2.5 TCR-Tg mice on the full NOD genetic background is strongly reduced, compared with control NOD.

Despite the use of the same diabetogenic TCR in both BDC2.5 models, different kinetics of disease development are observed in these mice. We asked whether these kinetic differences could be related to differences in the presence of non-lymphoid cell subtypes, and thus if these models could provide us with the opportunity to study the role of subtypes of non-lymphoid cells in diabetes development. Therefore, we have analyzed the pancreatic infiltration of various subsets of DC $\left(\mathrm{CD} 11 \mathrm{c}^{+}, \mathrm{NLDC}-145^{+}\right), \mathrm{M} \phi$ $\left(\mathrm{BM}^{+}, \mathrm{Monts}^{+} 4^{+}, \mathrm{ER}-\mathrm{MP} 23^{+}\right), \mathrm{T}$ cells $\left(\mathrm{CD} 4^{+}, \mathrm{CD}^{+}\right)$, and $B$ cells $\left(B 220^{+}\right)$in both the BDC2.5 $\mathrm{T}$ cell clone transfer and the BDC2.5 TCR-transgenic (BDC2.5 TCR-Tg) NOD model.

\section{Results} Pancreatic Histopathology of BDC2.5 TCR-Tg NOD Mice
as Compared with Wild-Type NOD Mice

The sequence of histopathological events preceding diabetes in wild-type NOD mice is described in Table 1. A representative infiltrate in a female NOD mouse is shown in Figure 1. In wild-type NOD mice, CD11c ${ }^{+}$ $\mathrm{DC}$ and $\mathrm{ER}-\mathrm{MP}_{2}{ }^{+} \mathrm{M} \phi$ were the first inflammatory cells appearing at the circumference of the islets at 4 to 7 weeks (Jansen et al, 1994). The influx of these cells was substantial in the early phases, whereas only a few $T$ cells (if any) were present at this stage. Thereafter, a slowly increasing recruitment of $T$ cells and of APC was observed. In the BDC2.5 TCR-Tg NOD, however, both APC and lymphocytes were recruited at the same time. From about 3 weeks of age onward, both APC and lymphocytes were present in substantial numbers at the edge of the islets, and large peri-insulitis areas were evident (Fig. 2). Moreover, the number of ER-MP23 ${ }^{+} \mathrm{M} \phi$ was either strongly decreased or they were absent from the islets (Fig. 2E).

In the phase of peri-insulitis, we observed again clear differences between the BDC2.5 TCR-Tg NOD and the wild-type NOD. From 3 weeks of age, the large peri-insular infiltrates stayed very pronounced in the BDC2.5 TCR-Tg NOD, until the end of our observation time. In wild-type NOD, however, welldeveloped peri-insular infiltrates containing substantial numbers of lymphocytes could not be seen before the age of 9 weeks (Jansen et al, 1994). In the BDC2.5 TCR-Tg NOD, massive lymphocyte infiltrates were clearly larger than the ones found in the wild-type NOD (Fig. 2), although the islet itself was not affected. The large lymphocyte infiltrates found in the transgenic animals had a high degree of organization. B and T lymphocytes were localized in separate areas (Fig. 2, C and D) within the infiltrate. As expected in an MHC class II restricted TCR transgenic mouse, the $\mathrm{T}$ cell infiltrate consisted primarily of $\mathrm{CD}^{+} \mathrm{T}$ cells (results not shown). DC were found in all compartments of the inflammatory infiltrate (Fig. 2B), but especially at the interface of intact $\beta$ cells and the T cell infiltrate (Fig. 2B). Moreover, two DC populations, characterized by CD11c and NLDC-145, were only partially overlap-

Table 1. Insulitis in Regular NOD Mice

\begin{tabular}{|c|c|}
\hline Stage & Comment \\
\hline Stage 0: & Intact islet as observed in non-diabetes-prone mice \\
\hline Stage I (wk 3): & $\begin{array}{l}\text { Intact islet, but an increase in perivascular and periductular extracellular matrix and a } \\
\text { perivascular increase of } \mathrm{CD} 11 \mathrm{c}^{+}, \mathrm{ER}-\mathrm{MP} 23^{+}, \mathrm{MOMA}-1^{+} \text {, and } \mathrm{BM} 8^{+} \mathrm{M} \phi \text { and } \mathrm{DC}\end{array}$ \\
\hline Stage II (wk 4-7): & $\begin{array}{l}\text { Islet surrounded by } \mathrm{DC} \text { and } \mathrm{M} \phi \text { with above-mentioned phenotypes; infiltration of } \\
\text { islets by } \mathrm{CD} 11 \mathrm{c}^{+} \mathrm{DC} \text {; a major infiltration by lymphocytes is still absent }\end{array}$ \\
\hline Stage III (wk 7-10): & $\begin{array}{l}\text { Para-insular recruitment of substantial numbers of } \mathrm{CD} 4^{+} \text {and } \mathrm{CD}^{+} \mathrm{T} \text { lymphocytes } \\
\text { and some B lymphocytes to the accumulation of } \mathrm{DC} \text { and } \mathrm{M} \phi\end{array}$ \\
\hline Stage IV (week 10-17): & Lymphocytes surround the islet (peri-insulitis) \\
\hline Stage $V(>$ wk 17): & Lymphocytes and ER-MP23 ${ }^{+}$and $\mathrm{BM}^{+} \mathrm{M} \phi$ infiltrate the islet \\
\hline Stage VI $(\gg 17$ wk): & Endstage; no insulin-producing cells detectable \\
\hline
\end{tabular}



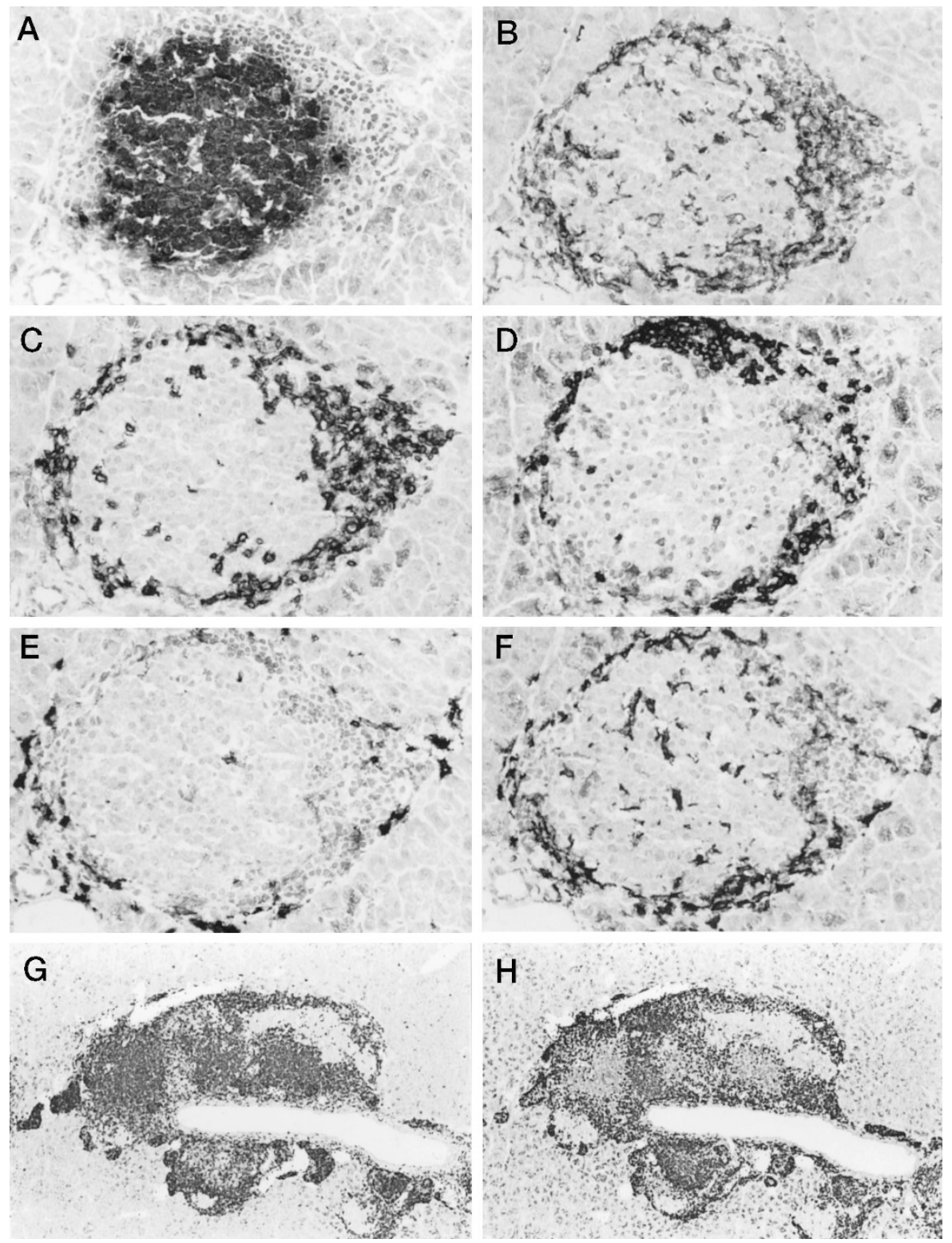

\section{Figure 1.}

Immunohistological characterization of a representative insulitis $(A$ to $F$; original magnification, $\times 200)$ and of a relatively rare lymphoid tissue-type of peri-insulitis ( $G$ and $\mathrm{H}$; original magnification, $\times 45$ ) in a female 15-week-old NOD mouse. (A) Anti-insulin staining, showing the $\beta$ cell mass; (B) CD11c, showing peri- and intra-islet accumulation of these DC; ( $C$ and D) CD3 (T cells) and B220 (B cells), respectively. Note that lymphocytes initially accumulate around the islet (peri-insulitis); (E) ER-MP23, showing that histiocytes accumulate at the islet-edge; (F) BM8, showing a peri-and intra-islet accumulation of these M $\phi$; (G and $\mathrm{H}$ ) CD3 (T cells) and B220 (B cells), respectively. Note the high grade of organization as normally found in secondary lymphoid tissues and in the BDC2.5 TCR-Tg NOD mouse.

ping. CD11c $\mathrm{C}^{+} \mathrm{DC}$ were seen accumulated at the border of the T cell infiltrate and intact $\beta$ cells, and were hardly present in the T cell area or in the islet mass (Fig. 2B). NLDC- $145^{+}$DC were also found at the $\beta$ cell/T cell border, but - in contrast to CD11 $\mathrm{c}^{+}$ $\mathrm{DC}$ - were also present intermingled with $\mathrm{T}$ cells and in the islet mass (not shown, Rosmalen et al, 1997). In addition, high endothelial venules (HEV) as well as lymph vessels could be found in the $T$ lymphocyte peri-insular areas (Fig. 2H). The peri-insular infiltrates of the BDC2.5 TCR-Tg NOD mouse thus histologically resemble secondary lymphoid tissue, especially mucosa-associated lymphoid tissue (eg,
Peyer's patches). The finding of Monts $-4^{+} M \phi$, normally present mainly in lymphatic tissue (Jutila et al, 1993), is in agreement with this (Fig. 2G). Occasionally, this lymphatic tissue adjacent to islets was also found in advanced stages in wild-type NOD mice (Fig. 1, G and $\mathrm{H}$ ), although the majority of NOD islets had a peri-insulitis with a non-characteristic architecture. Infiltration of leukocytes into the islets themselves was hardly observed in BDC2.5 TCR-Tg mice.

In wild-type NOD, destructive insulitis was histologically characterized by an early infiltration of $\mathrm{BM}^{+} \mathrm{M} \phi$ into the islets starting at 7 to 10 weeks. This infiltration 

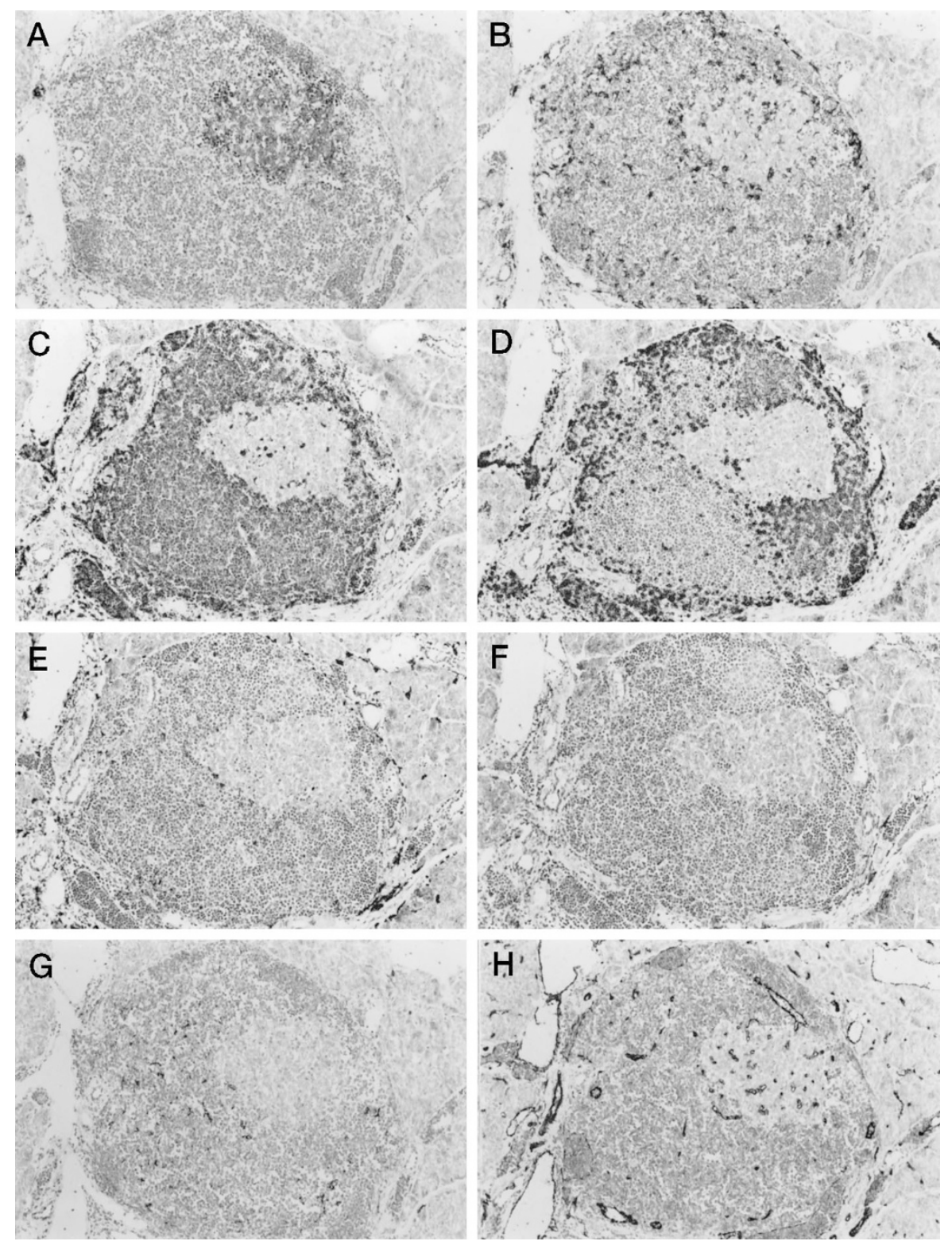

\section{Figure 2.}

Immunohistological characterization of a representative peri-islet lymphoid cell accumulation in a BDC2.5 TCR-Tg female NOD mouse, 4 weeks old. Original magnification $\times 90$. (A) Anti-insulin staining, showing the position of the $\beta$ cell mass; (B) CD11c, showing the accumulation of DC at the islet-edge and in between the accumulated lymphocytes; ( $C$ and D) CD3 (T cells) and B220 (B cells), respectively, showing the high grade of organization of the accumulated peri-islet lymphocytes in separate T- and B cell areas reminiscent of secondary lymphoid tissue; (E) ERMP-23, showing that histiocytes, one of the first types of M $\phi$ accumulating at the islet-edge in wild-type NOD insulitis, can be found only in small numbers at the periphery of the secondary lymphoid tissue; (F) BM8, showing the conspicuous absence of scavenger type $\mathrm{M} \phi$, similar to the situation seen in secondary lymphoid tissues; (G) Monts-4, showing that the lymphocyte peri-islet accumulation contains Monts- $4^{+} \mathrm{M} \phi$ normally seen in secondary lymphoid tissues; (H) ER-MP12, showing endothelial cells, particularly HEV and lymphatics characteristic of the secondary lymphoid tissue nature of the peri-islet lymphoid cell accumulations.

of $\mathrm{BM}^{+} \mathrm{M} \phi$ into the islets was especially pronounced in diabetes-prone female NOD mice, and was considerably less in male NOD mice that show a lower diabetes incidence. Destructive insulitis involving the influx of lymphocytes into the islet mass occurred from 15 weeks onward. In contrast to the regular NOD insulitis, $\mathrm{BM}^{+} \mathrm{M} \phi$ were virtually absent in the BDC2.5 TCR transgenic NOD infiltrates, especially in later stages of infiltration (Fig. 2f).

In summary, BDC2.5 TCR-Tg NOD mice developed extensive infiltrates resembling secondary lymphoid tissue, with a virtual absence of $\mathrm{BM}^{+} \mathrm{M} \phi$. Although the infiltrates developed early and were extensive, they did not lead to $\beta$ cell destruction.

\section{Pancreatic Histopathology of BDC2.5 T Cell Clone Transfer as Compared with Wild-Type NOD Mice}

In young ( $<14$ days) NOD mice receiving transfers of the BDC2.5 T cell clone, a very fast and aggressive insulitis was observed. Almost no insulin-producing cells could be detected at 10 days after the transfer. In 
relation to this, no sequential accumulation of APC and lymphocytes was observed. Only a very limited accumulation of ER-MP23 $+M \phi$, which in wild-type NOD are among the first to surround the islets, was found (Fig. 3E). In contrast, there was an increased accumulation of CD11C ${ }^{+}$DC (Fig. 3B), simultaneously with an accumulation of lymphocytes.

Compared with wild-type NOD mice, and certainly to BDC2.5 TCR-Tg mice, the accumulation of lymphocytes near the islets was minor. In the exocrine pancreas, few $B$ and $T$ cells were found. B cells were especially present around the islets, and a few were also infiltrating the islets (Fig. 3D). T cells (Fig. 3C) consisted of both CD4 ${ }^{+}$ and $\mathrm{CD}^{+}$cells; using immunofluorescent staining on isolated peri-islet $\mathrm{T}$ cells it has previously been determined that $\mathrm{CD}^{+} \mathrm{T}$ cells appeared in larger numbers as compared with $\mathrm{CD}^{+} \mathrm{T}$ cells (K. Haskins, ,personal communication, 1999). Infiltrates in BDC2.5 T cell clone transferred mice did not show any degree of histological organization. In addition, only limited numbers of Monts $-4^{+} \mathrm{M} \phi$ were found (not shown).

The most conspicuous observation in the BDC2.5 T cell clone-transferred mice was the strong and early infiltration with $\mathrm{BM}^{+}$scavenger type $\mathrm{M} \phi$ around the islets and into the islet mass (Fig. 3F). $\mathrm{BM}^{+} \mathrm{M} \phi$ were also seen scattered throughout the exocrine pancreas. This highly increased involvement of $\mathrm{BM}^{+} \mathrm{M} \phi$ contrasted the almost complete absence of such $\mathrm{M} \phi$ in the BDC2.5 TCR-Tg NOD inflammatory infiltrates. Also in the wild-type NOD insulitis, $\mathrm{BM}^{+} \mathrm{M} \phi$, although infiltrating the islets, were found in significantly lower numbers compared with the transfer model, especially in male but also in female mice.

In summary, BDC2.5 T cell clone-transferred NOD mice developed small unorganized infiltrates, with a high number of $\mathrm{BM}^{+} \mathrm{M} \phi$. These infiltrates appeared to be highly aggressive, as evidenced by the rapid loss of $\beta$ cells.

\section{Discussion}

Our data show that the (peri-)insulitis in the BDC2.5 T cell clone transfer model, the BDC2.5 TCR-Tg NOD model, and the wild-type NOD model follow distinct immunohistomorphological patterns with different involvement of non-lymphoid cell types. In the transfer model, a rapid destruction of the $\beta$ cells is associated with a progressive but relatively mild lymphocyte
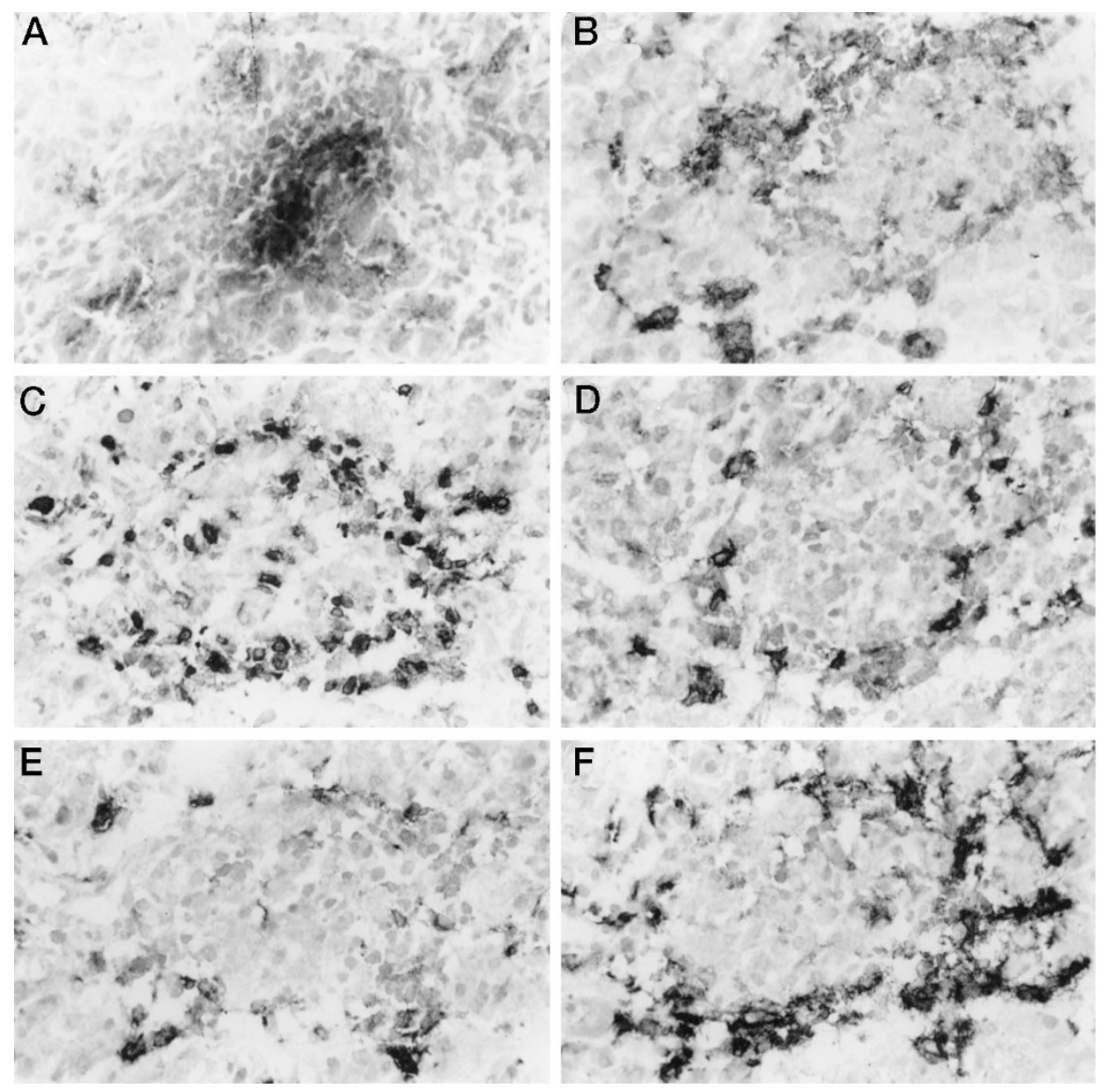

\section{Figure 3.}

Immunohistological characterization of a representative insulitis in a female NOD mouse (3 weeks old) transferred with the BDC2.5 T cell clone (10 days after the first transfer). Original magnification $\times 360$. (A) Anti-insulin staining, showing the $\beta$ cell mass; (B) CD11c, showing a relatively enhanced accumulation of DC at the islet edge as compared with wild-type NOD insulitis; ( $C$ and D) CD3 (T cells) and B220 (B cells), respectively. Note that there is hardly any peri-insulitis, but a relatively small infiltration of single cells as compared with the wild-type NOD and certainly as compared with the BDC2.5 TCR-Tg NOD; (E) ER-MP23, showing that histiocytes accumulate at the islet-edge like in the wild-type NOD insulitis; (F) BM8, showing an enhanced peri- and intra-islet accumulation of these M $\phi$. 
infiltration, whereas, compared with wild-type NOD, there is an extensive infiltration with $\mathrm{BM}^{+} \mathrm{M} \phi$. In contrast, the BDC2.5 TCR-Tg NOD model showed a very early development and a long-lasting presence of lymphoid tissue around otherwise intact islets, although there was a low incidence of diabetes. This lymphoid tissue was characterized by $\mathrm{T}$ and $\mathrm{B}$ cell zones, specific Monts $-4^{+}$lymph nodal $\mathrm{M} \phi$, and

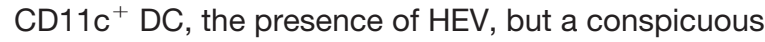
absence of $\mathrm{BM}^{+} \mathrm{M} \phi$.

The BDC2.5 T cell clone transfer model and the BDC2.5 TCR-Tg model also shared some histopathological features that differed from the wild-type NOD. The wild-type NOD showed an initial phase of periislet accumulation of $\mathrm{DC}$ and $\mathrm{M} \phi$ but a virtual absence of lymphocyte infiltration. However, both BDC2.5 models showed a simultaneous early peri-islet accumulation of APC and lymphocytes.

These data reveal several interesting differences in the kinetics of insulitis in NOD mouse models. In the TCR-Tg and in the transfer model, there is no separate phase of APC infiltration preceding lymphocyte infiltration, whereas this phase is present in wild-type NOD. The absence of a separate phase of APC accumulation indicates that the influx of lymphocytes takes place with accelerated kinetics in both BDC2.5 models. This acceleration of infiltration is most likely due to an increased frequency of autoreactive $T$ cells in both BDC2.5 models compared with wild-type NOD. Because of the relatively low frequency of islet-specific T cells in the initial naïve T cell pool of the wild-type NOD, its islet antigen-loaded DC need to interact with many naïve $T$ cells to encounter an islet antigen-specific-TCR. Such conditions are initially most optimally met in the pancreas-draining lymph nodes because of the recirculation of T cells via lymph nodal HEV and a specific accumulation in these nodes of islet antigen-loaded DC via the afferent lymph. The likelihood of such an encounter is minimal in the early small $\mathrm{T}$ cell infiltrates around the wild-type NOD islet. In both the BDC2.5 TCR-Tg and T cell clone transfer model, there are already many islet-specific $T$ cells in the repertoire early in life. This increases the likelihood of a specific DC-T cell encounter at the islet-edge itself. Therefore, a presentation of autoantigens in lymph nodes may not be required in both BDC2.5 models, whereas it is obligatory in wild-type NOD for clonal expansion of $\mathrm{T}$ cells.

Accelerated infiltration, however, does not lead to $\beta$ cell destruction in the BDC2.5 TCR-Tg NOD. The large, non-destructive infiltrates observed in this model are also observed in other TCR-Tg mousemodels with the cognate antigen expressed under the insulin promoter or only locally expressed in the thyroid (Akkaraju et al, 1997). Autoreactive T cells are not deleted in the thymus in these TCR-Tg mice because of a lack of systemic expression of the autoantigen. The large peri-insular infiltrates developing in such models also do not lead to actual destruction, since the autoreactive $T$ cells present likely have an impaired function. This impaired function of autoreactive T cells is reflected in a change in the sensitivity to TCR stimulation leading to diminished in vitro responsiveness to antigen and poor in vivo ability to provide $B$ cell help (Akkaraju et al, 1997). It remains to be determined whether the T cells in the BDC2.5 TCR Tg NOD are similarly dysfunctional. An alternative and, in our view, a more likely explanation for the strongly reduced $\beta$ cell destruction in BDC2.5 TCR-Tg NOD may be found in the number of $\mathrm{BM}^{+} \mathrm{M} \phi$ in the inflammatory infiltrate. These $\mathrm{BM}^{+} \mathrm{M} \phi$ are virtually absent in BDC2.5 TCR-Tg NOD, whereas they are abundantly present in the transfer model. In the wildtype NOD, $\mathrm{BM}^{+} \mathrm{M} \phi$ infiltrate the islets in diabetesprone females, but not in diabetes- (but not insulitis-) resistant males (Jansen et al, 1994). Together, these data strongly suggest that $\mathrm{BM}^{+} \mathrm{M} \phi$ are a histological marker of the progression from peri-insulitis to $\beta$-cell destruction and diabetes.

Various roles for these $\mathrm{BM}^{+} \mathrm{M} \phi$ could be envisaged. They may play a role simply in removing the cellular debris resulting from the autoimmune inflammation. Alternatively, $\mathrm{BM}^{+} \mathrm{M} \phi$ could be the ultimate effectors in the $\beta$ cell killing, possibly stimulated by $T$ cells. It is also possible that $\mathrm{BM}^{+} \mathrm{M} \phi$ induce some minor $\beta$ cell damage that - by virtue of enhanced antigen release - leads to antigenic spreading and a further local triggering of $\mathrm{T}$ cells. In that case, the peri-insular accumulated APC have a role in a final local $T$ cell stimulation of the infiltrated $T$ cells. Such a mechanism is compatible with a two-step model for the development of autoimmunity (Mueller et al, 1997). In the first step, initial priming of islet-specific $T$ cells with antigen occurs in the lymph node and results in the accumulation of lymphocytes in the target organ. In the second step, restimulation in the target organ by tissue-localized APC causes the lymphocytes to become destructive and clinically evident autoimmunity occurs. In general, the necessity of local restimulation of $T$ cells for their final activation would protect other tissues from bystander-induced damage by $T$ cells that are accidentally activated in other organs. The local microenvironment would then be an important determinant in APC function and thus in the ultimate outcome of the autoimmune infiltration.

Which factors could determine the differential influx of $\mathrm{BM}^{+} \mathrm{M} \phi$ in transgenic and transfer models? An important determinant may be an extremely high frequency of unactivated BDC2.5 TCR-carrying T cells in the BDC2.5 TCR-Tg versus a mildly raised frequency of activated and mature BDC2.5 T cells in the transferred NOD mice. Also in other models, the frequency of autoreactive $T$ cells has been shown to determine the fate of these cells (Förster et al, 1995). Another determinant may be an almost complete absence of $\mathrm{CD}^{+} \mathrm{T}$ cells, due to the $\mathrm{MHC}$ class II restricted TCR in the BDC2.5 TCR-Tg NOD mice compared with BDC2.5 T cell clone-transferred and wild-type NOD mice. However, transfer of CD8 $+\mathrm{T}$ cells in BDC2.5 TCR-Tg mice did not accelerate disease (André et al, 1996), making this possibility less likely. Alternatively, in the BDC2.5 TCR-Tg NOD mice, regulatory interactions between the transgenic $T$ cells and $B$ cells, or $\mathrm{CD}^{+} \mathrm{T}$ cells expressing endogenous $\mathrm{TCR} \alpha$ chains, 
may serve to attenuate the activity of the transgenic $T$ cells. This possibility is likely given that, if bred on a NODscid background, all of the BDC2.5 TCR-Tg mice develop diabetes by 3 to 5 weeks of age (Kurrer et al, 1997; Dobbs and Haskins, unpublished data). In the BDC2.5 TCR-Tg NODscid, there is a very extensive early infiltration, which is rapidly followed by full-blown diabetes. The infiltrate resembles pancreatitis and, in contrast to those observed in the BDC2.5 TCR-Tg NOD, is highly disorganized and invasive. The infiltrate comprises many $\mathrm{CD} 4^{+} \mathrm{V} \beta 4^{+} \mathrm{T}$ cells, likely expressing the cognate $\mathrm{BDC} 2.5 \mathrm{TCR}$, and $\mathrm{BM}^{+} \mathrm{M} \phi$ with a few ER-MP23 ${ }^{+} \mathrm{M} \phi$ scattered throughout.

On the basis of the differential involvement of nonlymphoid cell subsets in the presently investigated BDC-2.5-TCR-based models, we suggest that subtypes of non-lymphoid cells play different roles in diabetes development. Clearly, this notion needs further experimental investigation to delineate the functions of the distinct subtypes. However, this heterogeneity should be recognized when interpreting in vivo and in vitro studies concerning the role of nonlymphoid cells in diabetes development.

\section{Materials and Methods}

\section{Animals}

BDC2.5 TCR-Tg NOD mice and NOD mice used for T cell clone transfer studies were bred and maintained in the animal facilities at the Barbara Davis Center and the School of Medicine at the University of Colorado Health Sciences Center in Denver, Colorado. The incidence of diabetes in NOD/bdc mice is $50 \%$ to $60 \%$ in females and $30 \%$ to $40 \%$ in males by 28 weeks of age. In the Denver colony, the BDC2.5 TCR-Tg NOD mouse incidence of diabetes is $10 \%$ to $15 \%$ for both female and male mice by 28 weeks of age, and is thus strongly reduced compared with wild-type NOD mice. This was not the case with earlier backcrosses of BDC2.5 TCR-Tg, which only showed an extended lag period between initiation of insulitis and onset of diabetes (Katz et al, 1993). We wish to emphasize that the mice in the present study were BDC2.5 TCR-Tg on a full NOD background

BDC2.5 TCR-Tg NOD mice were killed at 3 to 4, 6 to 7,12 , or 16 weeks of age. For clone transfers, mice (12 to 13 days of age) received an injection of $10^{7} \mathrm{~T}$ cells, ip, and a week later received a second injection, again $10^{7}$ cells. Animals were killed 3 days after the second injection. The cloning and maintenance of the BDC$2.5 \mathrm{~T}$ cell clone was previously described (Haskins et al, 1988). Wild-type NOD mice were bred and kept at the facility of the Department of Immunology, Erasmus University in Rotterdam, The Netherlands. The incidence of diabetes in this colony is $80 \%$ to $90 \%$ in females and $50 \%$ to $60 \%$ in males by 30 weeks of age.

\section{Immunohistochemistry}

For each age, 5 mice were killed by cervical dislocation, pancreases were removed, embedded in OCT compound, and frozen on dry ice. Tissues were stored at $-80^{\circ} \mathrm{C}$ until immunohistochemistry was performed. Before sectioning, microscope slides were coated with a solution of $0.1 \%$ gelatin $/ 0.01 \%$ chromium-alum. Pancreas cryostat sections of $6 \mu \mathrm{m}$ were prepared, coded, and fixed for 2 minutes in $2 \%$ pararosaniline (De Jong et al, 1991). After a wash with phosphate buffered saline with $0.1 \%$ Tween-20 (Merck-Schuchardt, Hohenbrunn bei München, Germany) (PBS/Tween), slides were incubated with first step antibodies (Table 2) for 30 minutes at room temperature. BM8 (BMA Biomedicals, Augst, Switzerland) was used diluted 1:30 in PBS/Tween, antiinsulin (DAKO, Carpinteria, California) was used diluted 1:100 in PBS/Tween. All others were supernatants from hybridomas cultured at our department and used undiluted. Subsequently, slides were washed with PBS/ Tween and incubated with peroxidase-conjugated goat$\alpha$-hamster-immunoglobulins (Ig) (to detect N418), rabbit$\alpha$-guinea-pig-lg (to detect $\alpha$-insulin), or rabbit- $\alpha$-rat-lg (to detect all others) second step antibodies in the presence of $2 \%$ normal mouse serum for 30 minutes at room

Table 2. Antibodies Used for Immunohistochemical Study ${ }^{a}$

\begin{tabular}{lll}
\hline & \multicolumn{1}{c}{ Specificity } & Source \\
\hline Monoclonal Ab & & \\
RA3.6B2 & CD45R-antigen; B220-antigen & R. Coffman \\
BM8 & M $\phi$ with phagocytosing capacity & BMA \\
ER-MP12 & CD31-antigen; hematopoietic progenitors, endothelia & P. Leenen \\
ER-MP23 & mouse M $\phi$ galactose-/N-acetyl galactosamine & P. Leenen \\
KT3 & specific C-type lectin (MMGL); connective tissue M $\phi$ & ATCC \\
53-6.72 & CD3-antigen & ATCC \\
Monts-4 & CD8-antigen; Lyt2 & M. Jutila \\
H129-19 & M $\phi$ in lymphoid areas & P. Naquet \\
N418 & CD4-antigen; MT4 & ATCC \\
NLDC-145 & CD11C-antigen; DC & G. Kraal \\
Polyclonal Ab & DEC205; DC & DAKO \\
$\alpha$-insulin & & insulin
\end{tabular}

a Leenen et al, 1997 
temperature. After an additional wash with PBS/Tween, slides were incubated with $0.05 \%$ (w/v) Ni-di-aminobenzidine (Ni-DAB) with $0.02 \% \mathrm{H}_{2} \mathrm{O}_{2}$ and washed in water after 3 minutes. Finally, slides were counterstained for 3 minutes in nuclear fast red, dehydrated in a graded ethanol series, and mounted. For each staining run, one slide was stained with second antibody only as a control for endogenous peroxidase activity and nonspecific binding of the second step, and a section of spleen was included as a positive control.

\section{Acknowledgements}

The authors would like to thank Jonathan Katz, Diane Mathis, Christophe Benoist, and Willem van Ewijk for helpful discussions, Petra Assems and Geertje de Korte for secretarial assistance, and Tar van Os for preparation of the figures. This work was supported by grants from the Diabetes Fonds Nederland and travel grants from NWO-INSERM.

\section{References}

Akkaraju S, Ho WY, Leong D, Canaan K, Davis MM, and Goodnow CC (1997). A range of CD4 T cell tolerance: Partial inactivation to organ-specific antigen allows nondestructive thyroiditis or insulitis. Immunity 7:255-271.

André I, Gonzalez A, Wang B, Katz J, Benoist C, and Mathis D (1996). Checkpoints in the progression of autoimmune disease: Lessons from diabetes models. Proc Natl Acad Sci USA 93:2260-2263.

Bergman B and Haskins K (1994). Islet-specific T-cell clones from the NOD mouse respond to $\beta$-granule antigen. Diabetes 43:197-203.

De Jong JP, Voerman JSA, Leenen PJM, Van der SluijsGelling AJ, and Ploemacher RE (1991). Improved fixation of frozen lympho-haemopoietic tissue sections with hexazotized pararosaniline. Histochem J 23:392-401.

Förster I, Hirose R, Arbeit JM, Clausen BE, and Hanahan D (1995). Limited capacity for tolerization of $\mathrm{CD}^{+} \mathrm{T}$ cells specific for a pancreatic $\beta$ cell neo-antigen. Immunity 2:573585.

Haskins K and McDuffie M (1990). Acceleration of diabetes in young NOD mice with a CD4 ${ }^{+}$islet-specific $\mathrm{T}$ cell clone. Science 249:1433-1436.

Haskins K, Portas M, Bradley B, Wegmann D, and Lafferty K (1988). T-lymphocyte clone specific for pancreatic islet antigen. Diabetes 37:1444-1448.

Jansen A, Homo-Delarche F, Hooijkaas H, Leenen PJ, Dardenne M, and Drexhage HA (1994). Immunohistochemical characterization of monocytes-macrophages and dendritic cells involved in the initiation of the insulitis and $\beta$ cell destruction in NOD mice. Diabetes 43:667-675.
Jutila MA, Berg EL, Kroese FG, Rott L, Perry V, and Butcher EC (1993). In vivo distribution and characterization of two novel mononuclear phagocyte differentiation antigens in mice. J Leukoc Biol 51:30-39.

Katz JD, Benoist C, and Mathis D (1995). T helper cell subsets in insulin-dependent diabetes. Science 268:11851188.

Katz JD, Wang B, Haskins K, Benoist C, and Mathis D (1993). Following a diabetogenic $T$ cell from genesis to pathogenesis. Cell 74:1089-1100.

Kurrer MO, Pakala SV, Hanson HL, and Katz JD (1997). Beta cell apoptosis in T cell-mediated autoimmune diabetes. Proc Natl Acad Sci U S A 94:213-218.

Leenen PJM, Kraal G, and Dijkstra CD (1997). Markers of rodent myeloid cells. In: Herzenberg LA, Weir D, Herzenberg LA, and Blackwell C, editors. Handbook of experimental immunology. Malden, MA: Blackwell Science, Inc., 174.1174.25.

Liblau RS, Singer SM, and McDevitt HO (1995). Th1 and Th2 $\mathrm{CD}^{+} \mathrm{T}$ cells in the pathogenesis of organ-specific autoimmune diseases. Immunol Today 16:34-38.

Mueller R, Bradley LM, Krahl T, and Sarvetnick N (1997). Mechanism underlying counterregulation of autoimmune diabetes by IL-4. Immunity 7:411-418.

Peterson JD and Haskins K (1996). Transfer of diabetes in the NOD-scid mouse by CD4 T-cell clones. Differential requirement for CD8 T-cells. Diabetes 45:328-336.

Rosmalen JGM, Leenen PJM, Katz JD, Voerman JSA, and Drexhage HA (1997). Dendritic cells in the autoimmune insulitis in NOD mouse models of diabetes. In: RicciardiCastagnoli P, editor. Dendritic cells in fundamental and clinical immunology, vol.3, New York: Plenum Publishing corporation, 291-294.

Serreze DV, Chapman HD, Varnum DS, Hanson MS, Reifsnyder PC, Richard SD, Fleming SA, Leiter ED, and Shultz LD (1996). B lymphocytes are essential for the initiation of T cell mediated autoimmune diabetes: Analysis of a new "speed congenic" stock of NOD.Ig $\mu^{\text {null }}$ mice. J Exp Med 184:20492053.

Tisch R and McDevitt H (1996). Insulin-dependent diabetes mellitus. Cell 85:291-297.

Voorbij HAM, Jeucken PHM, Kabel PJ, De Haan M, and Drexhage HA (1989). Dendritic cells and scavenger macrophages in pancreatic islets of prediabetic BB rats. Diabetes 38:1623-1629.

Wang B, Gonzales A, Benoist C, and Mathis D (1996). The role of $\mathrm{CD}^{+} \mathrm{T}$ cells in the initiation of insulin-dependent diabetes mellitus. Eur J Immunol 26:1762-1769. 